\title{
Current and potential geographical distribution of Platymeris biguttatus (Linnaeus, 1767) with description of nymphs
}

\author{
Dominik Chłond, Agnieszka Bugaj-Nawrocka* and Łukasz Junkiert
}

\begin{abstract}
Background: The description of Platymeris biguttatus (Linnaeus 1767) nymphal instars as well as the prediction of the potentially suitable ecological niche was the main goal of this study. Our research was based on 258 specimens of $P$. biguttatus species of museum collections. A set of 23 environmental predictor variables covering Africa was used at ecological niche modeling - a method performed using the Maxent software to prepare potential distribution maps for this species.

Results: The results suggested the most suitable areas seen as potentially suitable ecological niche for $P$. biguttatus in Africa. A jackknife test showed that temperature seasonality and percentage of tree cover were among the most important environmental variables affecting the distribution of the species. The analysis of climate preferences shows that most of the potentially suitable niches for this species were located in the area of tropical savanna climate, with a small participation of tree vegetation.
\end{abstract}

Conclusions: $P$. biguttatus was only known to be widely distributed in the tropical part of continental Africa. Thanks to the ecological niche modeling methods and the museum data on the occurrence of the species, we introduced new information about potentially suitable ecological niches and the possible range of distribution.

Keywords: Africa; Comparison of niches; Ecological niche modeling; Habitat suitability; Species distribution

\section{Background}

Platymeris biguttatus (Linnaeus 1767) is one of thirteen species of the genus Platymeris Laporte 1833 described so far. It is a medium-sized genus belonging to the subfamily Reduviinae, and all known species of these assassin bugs are large-sized insects, distributed exclusively in Africa (Maldonado Capriles 1990). P. biguttatus (L.) is widely distributed in the tropical part of continental Africa, and it can be easily recognized amongst the other representatives of this genus by the white spots on the hemelytra, yellow bands on the legs and black connexiva. Redescription of the species as well as notes on its biology in captivity were published by Li et al. (2010). Although the article contains pictures and presents the biology of nymphs of this species, it does not provide a description of each nymphal instars. Due to the availability

\footnotetext{
* Correspondence: abugaj-nawrocka@us.edu.pl

Department of Zoology, Faculty of Biology and Environmental Protection, University of Silesia, Bankowa 9, 40-007 Katowice, Poland
}

of a large number of individuals of this species deposited in European museum collections as well as numerous live specimens breed in captivity in our laboratory, examination and description of morphology of each nymphal instars of this species was possible, and it is provided in the present paper.

Ecological niche modeling was introduced into this study to learn more about some ecological aspects of the mentioned species. This method is widely used in the faunal and floral studies, and it is very useful for biogeography, e.g., to identify potential migration routes of species (mostly invasive ones), to plan the establishment of protected areas, or even to predict the effects of climate change (Beck 2012; Berzitis et al. 2014; Ochoa-Ochoa et al. 2009; Wieczorek and Bugaj-Nawrocka 2014).

As many factors, both biotic and abiotic, affect the distribution of species or plant communities, it is important to choose the right method and environment variables. Our study was aimed at determining which niches might be potentially suitable for P. biguttatus, interpreting the 
influence of predictors on the distribution and comparison with the results obtained for Platymeris rhadamanthus (Chłond and Bugaj-Nawrocka 2014). The maximum entropy model (Maxent) is based on a machine learning method and has many advantages (e.g., it avoids commission errors, incorporates interactions between variables, utilizes continuous and categorical data) that make it a well-suited method for species distribution modeling (Phillips et al. 2006). It is also worth to note that Maxent seems to work better than other software and has a better performance in predicting the distribution of species, especially when a limited number of sample localities is available (Elith et al. 2006; Hernandez et al. 2006; Papeş and Gaubert 2007).

\section{Methods}

\section{Taxonomy}

Numerous live specimens breed in captivity in our laboratory were available at various stages of nymphs. External structures of nymph specimens were examined using a stereoscopic microscope Olympus SZH10 (Olympus Corporation, Shinjuku-ku, Japan). All drawings were made using a camera lucida. Measurements are given in millimeters. Measurements were performed on 30 individuals of each nymphal stage - a total of 150 individuals were measured. Photos were taken with a Sony SLT-A37 camera with additional 13-mm and 31-mm extension tubes.

\section{Material}

See Additional file 1 for a detailed list of all examined individuals of $P$. biguttatus. This list, as well as the list in Additional file 2, provides the information about occurrence localities.

\section{Occurrence data}

A total of 50 occurrence localities were assembled for the species P. biguttatus. It has been localized in Senegal, Gambia, Guinea, Mali, Ivory Coast, Togo, Benin, Niger, Nigeria, Chad, Sudan, Ethiopia, Somalia, the Democratic Republic of Congo, Uganda, Kenya, Tanzania, Zambia, Zimbabwe, and Mozambique (Figure 1). All occurrence data was based on the detailed review of 258 specimens studied in museum collections (see abbreviations for depositories in Additional file 1). Records with unspecified
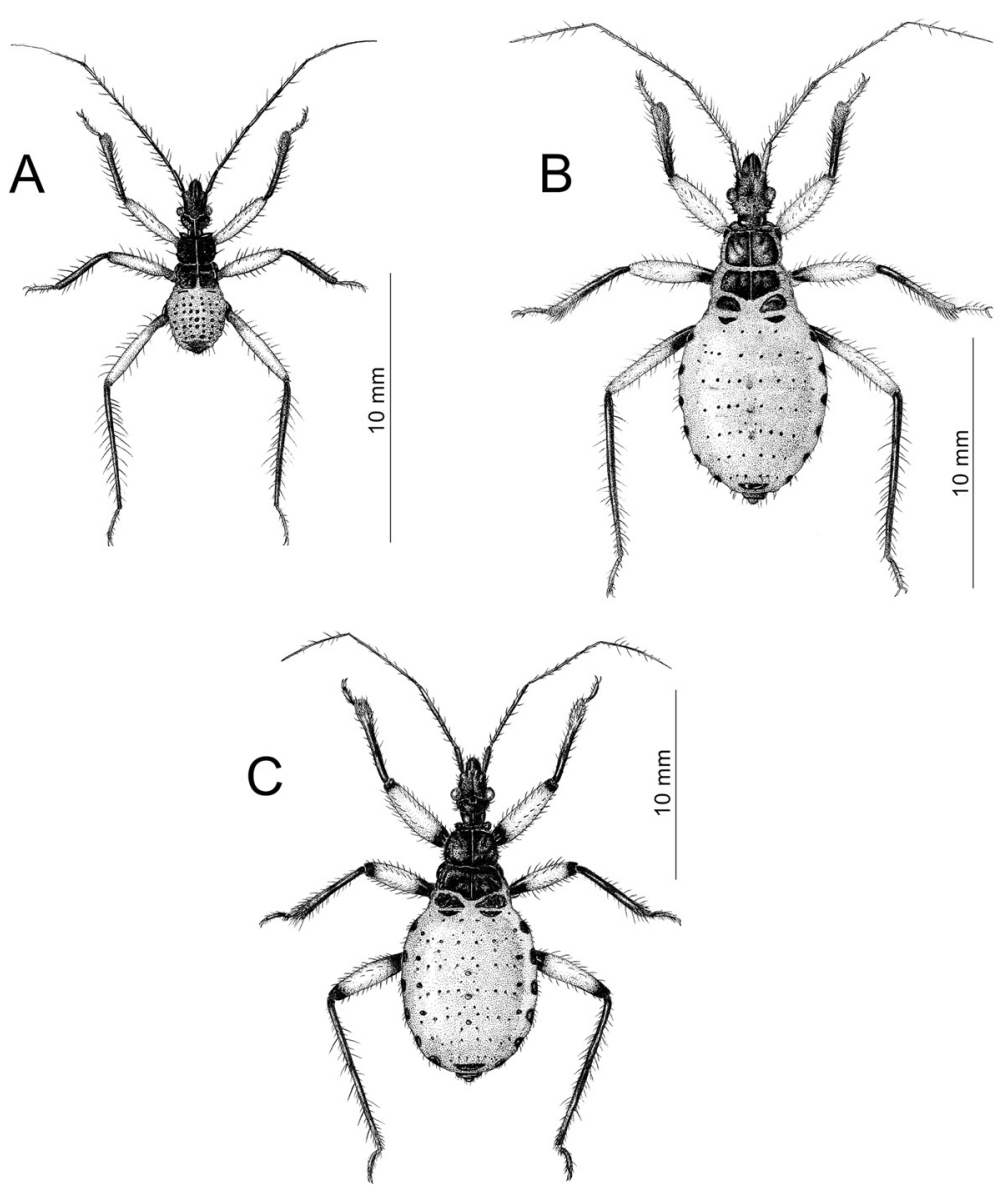

Figure 1 Dorsal habitus of the first three instar nymphs of $P$. biguttatus. (A) first instar nymph; (B) second instar nymph; (C) third instar nymph. 
or unknown localities were not used. All localities were georeferenced using Google Earth 7.1.2.2041 (Google Inc. 2013, Mountain View, CA, USA) (geographical projection, decimal degrees, datum: WGS84).

\section{Environmental predictors}

As potential predictors of habitat distribution for P. biguttatus, environmental variables were used. The study was based on bioclimatic variables which were downloaded from WorldClim 1.4 dataset (Hijmans et al. 2005; http://www.worldclim.org/bioclim). The Global Land One-km Base Elevation Project (GLOBE) (GLOBE Task Team and others 1999; http://www.ngdc.noaa.gov/mgg/ topo/globe.html) provided a digital elevation model (DEM). Also a layer of the tree cover continuous fields was used. It shows vegetation as continuous fields of land cover, where every pixel has a percentage value for tree cover (DeFries et al. 2000; http://glcf.umd.edu/data/ treecover). All variables were cut to the boundaries of Africa and a spatial resolution of 30 arc-seconds (approximately $1 \mathrm{~km}$ ) was chosen.

To determine the possible climatic preferences, results for potential ecological niche were compared to the Köppen-Geiger climate classification system updated by Peel et al. (2007).

\section{Ecological niche modeling}

Maxent software (version 3.3.3 k), based on maximum entropy algorithm, was used to develop a species distribution model. The following settings were chosen: maximum number of background points $=10,000$, convergence threshold $=0.00001$, regularization multiplier $=1$, maximum number of iterations $=5,000$. These settings allowed for adequate time for model convergence (Stohlgren et al. 2011; Elmore et al. 2013; Solhjouy-Fard and Sarafrazi 2013). A 50-fold cross-validation was run using the full occurrence dataset randomly split into a $25 \%$ test and $75 \%$ training dataset (Phillips et al. 2006; Phillips and Dudík 2008). The logistic output of Maxent was used, which gives the results for the prediction values ranging from 0 (unsuitable habitat) to 1 (optimal habitat). A jackknife test was selected to show relative importance of each predictor by comparing models with all environmental variable combinations by measuring variable importance. A receiver operating characteristic (ROC) analysis was used to assess the quality of the model (Fielding and Bell 1997). A measure of the area under the ROC curve (AUC) was also calculated. It showed the performance of the model and the weight of both the omission error and the commission error. The AUC assumes a range of values from 0 to 1 , but the useful models produce AUC values from 0.7 to 0.9 , and AUC values above 0.9 characterize models with almost perfect discrimination (Fielding and Bell 1997; Pearce and Ferrier 2000). It is worth noting that recent studies indicate that the model accuracy (AUC values) depends on the number of records, the used algorithm, and the type of data used (Raes and ter Steege 2007; Wisz et al. 2008; Aguirre-Gutiérrez et al. 2013), so it should not be considered to be the most important determinant of the accuracy of the model.

Raw environmental data was extracted from all raster layers at species occurrence records using SAGA GIS 2.1.0 (SAGA Development Team 2013). A Spearman rank correlation was performed in the $\mathrm{R}$ software (version 3.0.2) ( $R$ Development Core Team 2011) using Rattle package (version 3.0.2 r169) (Williams 2011) to minimize the number of variables by discarding these which were highly correlated $(r>0.75)$. The variables that did not have any significant contribution to the model were removed, and six uncorrelated environmental factors were selected (Table 1).

As species occurrence points came from the museum data and were not collected randomly, a bias file was provided during Maxent modeling. The bias grid file was generated in SAGA GIS, weighted by a Gaussian kernel with a standard deviation (SD) of $200 \mathrm{~km}$ (see Elith et al. 2010). To avoid extreme values, the resulting grid was scaled to have a maximum of 20 and a minimum of 1 .

Moreover, to identify niche overlap from Maxent model predications for $P$. biguttatus and $P$. rhadamanthus (Chłond and Bugaj-Nawrocka 2014), SAGA GIS 2.1.0 software was used. The ASCII median output files of Maxent for both species were reclassified and then added together to obtain a raster that contained the suitable niche classes for both species.

\section{Results}

Taxonomy

Description of nymphs

First instar (Figure 1A) Color: Head and thorax black with dark brown ventral parts and red ecdysial lines. Antennae with black scapus and pedicellus, both segments covered by black setae. Basiflagellomere with black basal

Table 1 Variables selected for the modeling

\begin{tabular}{llllll}
\hline Variables & Description & \multicolumn{3}{l}{ Occurrences } \\
\cline { 3 - 6 } & & Min. & Median & Mean & Max. \\
\hline Bio02 & Mean diurnal range & 7.1 & 11.6 & 11.7 & 15.8 \\
Bio04 & Temperature seasonality & 0.47 & 1.24 & 1.47 & 3.3 \\
Bio06 & Minimal temperature & 7.3 & 16.1 & 16.1 & 22.8 \\
& of coldest month & & & & \\
Bio14 & Precipitation of driest month & 0 & 5 & 11.5 & 59 \\
Bio15 & Precipitation seasonality & 32 & 77.5 & 88.6 & 157 \\
Tree & Tree vegetation cover & 0 & 13 & 14 & 35 \\
\hline
\end{tabular}

Variables with explanations and altitude ranges for the localities with occurrence of $P$. biguttatus. Temperatures given in ${ }^{\circ} \mathrm{C}$; precipitations given in $\mathrm{mm}$; vegetation cover (Tree) given in \%. 
part and gradually paler into the apex. Medial part of basiflagellomere greyish, apical part white; both parts with distinctly visible black rings in the location of black setae. Distiflagellomere greyish with black basal part, covered by black and white setae. Legs bicolorous with dark brown coxa and trochanters. Femurs yellow with dark brown basal part of hind femur. Tibiae and tarsi dark brown. Abdomen red with black sclerotized points and plates on dorsal part and dark brown ostioles of dorsal abdominal glands. Tip of abdomen black. Setae on head, thorax, and abdomen black. Legs with pale and dark brown setae.

Structure: Body dull with shiny head and thorax, covered by various-sized setae. Head with medium-sized and long setae. Ecdysial line visible in lateral parts of transversal suture of the head. In the middle part ecdysial line is u-shaped and connected with longitudinal ecdysial line placed in $1 / 2$ of postocular part of the head and on the neck. Clypeus covered by long setae, mandibular, and maxillary plates covered by medium-sized setae. Labrum visible in all length of first visible labial segment. Scapus short and wide with distinct enlargement in basal part. Pedicellus slightly thinner than scapus, both segments covered by long, erected, and robust setae. Basiflagellomere the longest, distiflagellomere slightly shorter than basiflagellomere, both segments covered by long, thin, erected, and regularly placed setae. Distiflegallomere covered also by pale short, adherent setae (except 1/5 of basal part). Tergites of thorax covered by a few various-sized setae, two of them are visible outside the area of tergites. Posterior margin of thorax in dorsal view with two elongated sclerotizations, placed laterally. Pro-, meso-, and metaepleura with numerous, short, and robust spine-like processes. Thorax beneath covered by three transversal rows of few various-sized setae. Legs covered by long, regularly arranged setae. Abdomen dorsally covered by very dense and very short setae. On each abdominal segment visible long setae placed on distinct sclerotized plates and arranged in transversal rows - six setae on each segment, except for the row on second abdominal segment, which contains only four setae. A pair of long setae visible on lateral margins of each abdominal segment. On segments IV to VI visible large ostioles of dorsal abdominal glands. Segments IX and $\mathrm{X}$ with visible sclerotized plates of tergites. Ventral side of abdomen covered by transversal rows of long and thin setae (one row on each segment) without any sclerotized elements.

Measurements (in mm): Body length: 7.2 to 7.5 ; head length: 1.55 to 1.61; head width: 1.03 to 1.05 ; length of anteocular part: 0.88 to 0.9 ; length of postocular part: 0.4 to 0.41 ; length of synthlipsis: 0.54 to 0.55 ; lengths of antennal segments I:II:III:IV: 0.65 to $0.67: 1.7$ to $1.75: 2.6$ to 2.64: 2.54 to 2.58 ; lengths of rostral segments I:II:III: 0.55 to $0.57: 0.9$ to 0.92 : 0.43 . to 0.46 ; maximum length of thorax: 1.65 to 1.7 maximum width of thorax: 1.88 to 1.91; maximum width of abdomen: 3.1 to 3.19 ; maximum length of abdomen: 3.78 to 3.86 .

Second instar (Figure 1B) Color: Head and thorax black with dark brown ventral parts and red ecdysial lines. Antennae with dark brown scapus and pedicellus, both segments covered by black setae. Apex of pedicellus pale. Basiflagellomere greyish with black spots and dark brown setae. Distiflagellomere dark brown with dark setae on 1/4 of basal part and pale setae on 3/4 of apical part. Legs bicolorous with brown coxa and trochanters. Femurs yellow with brown basal and apical part of femurs; $1 / 4$ of basal part of hind femur brown. Tibiae dark brown with slightly paler apex. Tarsi brown. Legs covered by dark setae. Abdomen red with black sclerotized parts. Ostioles of dorsal abdominal glands light brown. Tip of abdomen black. Setae on head, thorax, and abdomen black. Legs with pale and dark brown setae.

Structure: Body dull with shiny head and thorax, covered by medium-sized setae. Head and thorax with dense and very small granulations as well as several large granules. Ecdysial line visible in lateral parts of transversal suture of the head and on the anterior margin of the eyes. In the middle part, the ecdysial line is u-shaped and connected with longitudinal ecdysial line placed in $1 / 2$ of postocular part of the head and on the neck. Clypeus covered by long setae, mandibular, and maxillary plates covered by medium-sized setae. Labrum visible in $1 / 2$ of basal part of first visible labial segment. Scapus short and wide with distinct enlargement in basal part. Pedicellus slightly thinner than scapus, both segments covered by long, erected, and robust setae. Basiflagellomere the longest, distiflagellomere slightly shorter than basiflagellomere. Basiflagellomere covered by long, thin, erected, and regularly placed setae, setae placed on the shorter apex. Distiflegallomere covered in $1 / 3$ of basal part by regularly arranged and long setae (dark with pale apices) and in $2 / 3$ of apical part by few long, erected setae, and very dense, short, and adherent setae (pale). Collar of pronotum with distinctly developed lateral calli. Calli with one short and robust setae. Tergites of thorax covered by a few varioussized setae, long, and robust setae placed on distinct granulations. Lateral margins of tergites of thorax covered by medium-sized and short setae. Posterior margin of tergite of prothorax flattened. Tergite of mesothorax with two symmetrical arranged setae placed on large granulations. Tergites of metathorax with five medium-sized setae placed on granulations. Pro-, meso-, and metaepleura with numerous, short, and robust spine-like processes. Ventral part of pronotum with well-formed stridulitrum. On the sides of stridulitrum visible conical spines with one setae on the apex. Anterior margin of mesothorax 
with double ridge visible ventrally. Mesothorax beneath covered by one transversal row of four medium-sized setae. Unsclerotized parts of metathorax as well as posterior part of mesothorax covered by very short and dense setae (absent in the other parts of thorax). Legs covered by various-sized, regularly arranged setae. Abdomen dorsally covered by very dense and very short setae. II abdominal segment with two crescent-shaped sclerotizations. On each abdominal segment visible long setae placed on distinct sclerotized plates and arranged in transversal rows. Muscle attachments are visible in lateral parts of II to VIII abdominal segment in dorsal and ventral view. Dorsolateral sclerotizations covered by medium-sized setae visible on abdominal segments III to IX. On segments IV to VI visible a medium-sized ostioles of dorsal abdominal glands. Segments IX and X with visible sclerotized plates of tergites. Ventral side of abdomen covered by transversal rows of long and thin setae. A sclerotization of sternites in middle part visible on abdominal segments VIII and IX.

Measurements (in mm): Body length: 10.8 to 11.5; head length: 2.17 to 2.3 ; head width: 1.55 to 1.59 ; length of anteocular part: 1.21 to 1.25 ; length of postocular part: 0.69 to 0.72 ; length of synthlipsis: 0.89 to 0.93 ; lengths of antennal segments I:II:III:IV: 0.96 to $1.02: 2.51$ to 2.55: 3.33 to $3.37: 2.95$ to 2.99 ; lengths of rostral segments I:II:III: 0.89 to 0.92 : 1.04 to 1.07 : 0.52 to 054 ; maximum length of thorax: 2.91 to 2.95; maximum width of thorax: 2.74 to 2.83 ; maximum width of abdomen: 4.48 to 4.55 ; maximum length of abdomen: 5.43 to 5.54 .

Third instar (Figure 1C) Color: Head and thorax black with dark brown ventral parts and red ecdysial lines. Antennae with black scapus and pedicellus, both segments covered by black setae. Basiflagellomere greyish with black spots and dark brown setae. Distiflagellomere greyish with dark setae on $1 / 3$ of basal part and pale setae on $2 / 3$ of apical part. Legs bicolorous with dark brown to black coxa and trochanters. Femurs yellow with black basal and apical part of femurs; $1 / 4$ of basal part of hind femur black. Tibiae black with slightly paler apex and fossula spongiosa. Tarsi brown with paler ventral side. Legs covered by brown and black setae. Abdomen dark brown with black sclerotized parts. Ostioles of dorsal abdominal glands brown. Tip of abdomen black. Setae on head, thorax, and abdomen black. Legs with pale, brown, and black setae.

Structure: Body dull with shiny parts of head and thorax, covered by medium-sized setae. Head and thorax as well as sclerotized parts of the abdomen with dense and various-sized granulations. Ecdysial line visible in lateral parts of transversal suture of the head and on the anterior margin of the eyes. In the middle part the ecdysial line is reverse omega shaped and connected with longitudinal ecdysial line placed in $1 / 2$ of postocular part of the head and on the neck. Clypeus, mandibular, and maxillary plates covered by medium-sized setae, Labrum wide, visible in $1 / 2$ of basal part of first visible labial segment. Scapus short and wide with distinct enlargement in basal part. Pedicellus distinctly thinner than scapus, both segments covered by long, erected, and robust setae. Basiflagellomere the longest, distiflagellomere slightly shorter than basiflagellomere. Basiflagellomere covered by medium-sized, thin, suberected, and regularly placed setae. Distiflegallomere covered in $1 / 3$ of basal part by regularly arranged and long setae (brown) and in $2 / 3$ of apical part by few medium-sized, erected setae, and very dense, short, and suberected setae (pale). Collar of pronotum with distinctly developed lateral calli and small, regularly arranged granulations. On anterior margin of collar a line of medium-sized and dense setae placed parallel to the neck. Calli with one long and robust and a few short setae. Tergites of thorax covered by various-sized (mostly short) setae, placed on large granulations. Lateral margins of tergites of thorax covered by medium-sized setae. Tergite of prothorax with diagonal short sulci placed between lines of granulations. Tergite of mesothorax with medium-sized setae placed on large granulations in the middle and on lateral margins. Tergites of metathorax with medium-sized setae placed on granulations. Pro-, meso-, and metaepleura with numerous, small, regularly arranged granulations. Ventral part of pronotum with well-formed stridulitrum. On the sides of stridulitrum, visible conical spines with four setae on the apex. Pro- and mesocoxal cavities partially sclerotized; mesocoxal cavity with row of three long and robust erected setae placed postolaterally on inner margin of sclerotized part of cavity. Mesothorax beneath covered by one transversal row of medium-sized setae and with partially sclerotized metacoxal cavity. Unsclerotized parts of metathorax as well as posterior part of mesothorax with dense punctuation. Legs covered by various-sized, regularly arranged setae. Abdomen dorsally covered by short setae. First abdominal spiracle distinctly visible, placed near erected, medium-sized setae. II abdominal segment with two crescent-shaped sclerotizations covered by small, regularly arranged granulations. On each abdominal segment, visible medium-sized setae placed on distinct sclerotized plates and arranged in transversal rows. Muscle attachments visible in lateral parts of II to VII abdominal segment in dorsal and ventral view. Dorsolateral sclerotizations covered by medium-sized setae visible on abdominal segments III to IX. On segments IV to VI visible medium-sized ostioles of dorsal abdominal glands (ostiole on segment VI smaller). Segments IX and $\mathrm{X}$ with visible sclerotized plates of tergites. Ventral side of abdomen wedge shaped, covered by transversal rows of long and thin setae and with distinctly visible dark spiracles and muscle attachments. A sclerotization of sternites in middle part visible on abdominal segments 
VIII and IX; sclerotizations covered by long and very short setae.

Measurements (in mm): Body length: 13.7 to 14.8 ; head length: 2.88 to 2.95; head width: 2.07 to 2.11 ; length of anteocular part: 1.5 to 1.59 ; length of postocular part: 0.59 to 0.64 ; length of synthlipsis: $0.99-1.06$; lengths of antennal segments I:II:III:IV: 1.1 to 1.12 : 3.2 to 3.23 : 3.7 to 3.74 : 3.24 to 3.26 ; lengths of rostral segments I:II:III: 1.29 to 1.32: 1.24 to $1.25: 0.7$ to 0.8 ; maximum length of thorax: 4.01 to 4.06 ; maximum width of thorax: 3.2 to 3.32 ; maximum width of abdomen: 5.56 to 5.62; maximum length of abdomen: 6.91 to 7.12 .

\section{Fourth instar (Figure 2A)}

Color: Head and thorax black with dark brown ventral parts and red ecdysial lines. Antennae with black scapus and pedicellus, both segments covered by black setae. Basiflagellomere dark brown with pale spots and dark brown setae. Distiflagellomere brown with paler spots, covered by dark and pale setae. Legs bicolorous. Coxa dark brown with black apical margin. Trochanters black. Femurs yellow with black basal and apical part of femurs; $1 / 3$ of basal part of hind femur black. Tibiae black with slightly paler apex and fossula spongiosa. Fore and middle tarsi brown with paler ventral side, hind tarsi black. Legs covered by brown and black setae. Abdomen dark brown with black sclerotized parts. Ostioles of dorsal abdominal glands dark brown. Tip of abdomen black. Setae on head, thorax, and abdomen black. Legs with brown and black setae.

Structure: Body dull with shiny parts of head and thorax, covered by medium-sized setae. Head and thorax as well as sclerotized parts of the abdomen with various-sized granulations. Ecdysial line visible in lateral parts of transversal suture of the head and on the anterior margin of the eyes. In the middle part, ecdysial line $\mathrm{w}$-shaped and connected with longitudinal ecdysial line placed in $1 / 2$ of postocular part of the head and on the neck. Clypeus, mandibular, and maxillary plates covered by mediumsized setae. Labrum wide, visible almost $1 / 2$ of basal part of first visible labial segment. Scapus short and wide, slightly curved, club-shaped with enlargement in basal part. Pedicellus distinctly thinner than scapus. Scapus covered by long, suberected, and robust setae. Pedicellus covered by suberected and adherent, long, robust setae. Basiflagellomere the longest, covered by medium-sized, thin, suberected, and regularly placed setae. Distiflegallomere covered by regularly arranged and long setae (brown and pale) and by very dense, short, and suberected, pale setae (except basal part). Collar of pronotum distinctly separate with large lateral calli and small, regularly arranged granulations. On anterior margin of collar, a line of medium-sized setae placed subparallel to the neck. Calli with few robust and long setae. Tergites of thorax covered

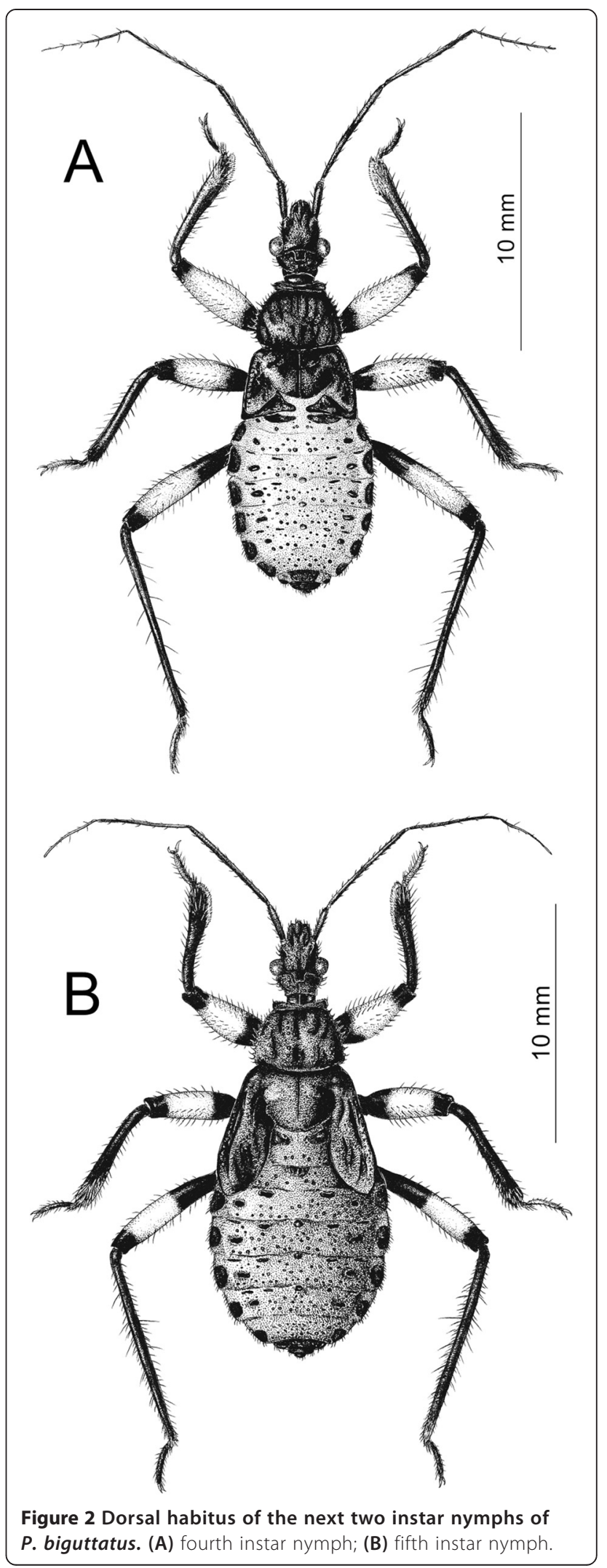


by various-sized (mostly short) setae, placed on large granulations. Lateral margins of tergites of thorax covered by medium-sized and very dense setae. Tergite of prothorax with diagonal short sulci placed between lines of granulations and with two distinct concaves in anterior part. Tergite of mesothorax with distinctly visible wing pads, covered by small granulations and medium-sized setae placed on large granulations. Tergites of metathorax with medium-sized setae placed on granulations. Tergites of meso- and metathorax with a few large, conical granulations with long setae. Pro-, meso-, and metaepleura with numerous, small, regularly arranged granulations. Ventral part of pronotum with well-formed stridulitrum. On the sides of stridulitrum, visible conical spines with four setae on the apex. Pro- and mesocoxal cavities almost completely sclerotized. Unsclerotized parts of metathorax as well as posterior part of mesothorax with slightly visible punctuation. Legs covered by various-sized setae, visibly much denser on ventral side. Abdomen dorsally covered by short setae. First abdominal spiracle large. II abdominal segment with two crescent-shaped, elongated sclerotizations covered by small, regularly arranged granulations. On each abdominal segment, visible medium-sized setae placed on distinct sclerotized plates and arranged in transversal rows. Muscle attachments very distinctly visible in lateral parts of II to VIII abdominal segment in dorsal and ventral view. Dorsolateral sclerotizations covered by medium-sized setae visible on abdominal segments III to IX. On segments IV to VI visible medium-sized ostioles of dorsal abdominal glands (ostiole on segment VI very small). Segments IX and X with visible sclerotized plates of tergites. Ventral side of abdomen flattened, covered by transversal rows of long and thin setae and with distinctly visible dark spiracles and two rows of muscle attachments. A sclerotization of sternites in middle part visible on abdominal segments VIII and IX (both connected); sclerotizations covered by long and very short setae.

Measurements (in mm): Body length: 19.4 to 20.5; head length: 3.75 to 3.8 ; head width: 2.8 to 2.84 ; length of anteocular part: 2.01 to .2 to 04 ; length of postocular part: 0.89 to 0.93 ; length of synthlipsis: 1.9 to 2.02 ; lengths of antennal segments I:II:III:IV: 1.83 to $1.86: 4.7$ to $4.76: 4.8$ to $4.9: 3.55$ to 3.6 ; lengths of rostral segments I:II:III: 1.89 to $1.93: 1.75$ to $1.8: 0.91$ to 0.95 ; maximum length of thorax: 6.2 to 6.3; maximum width of thorax: 5.1 to 5.18; maximum width of abdomen: 8.82 to 8.95 ; maximum length of abdomen: 10.5 to 11.1 .

Fifth instar (Figure 2B) Color: Head and thorax black with dark brown ventral parts and red ecdysial lines. Antennae with black scapus and pedicellus, both segments covered by black setae. Basiflagellomere and distiflagellomere brown with paler spots, covered by dark and pale setae. Legs bicolorous. Coxa dark brown with black basal part and apical margin. Trochanters black. Femurs yellow with black basal and apical part - $1 / 3$ of basal part of fore and middle femurs black, $1 / 2$ of basal part of hind femur black. Tibiae black with pale fossula spongiosa. Tarsi black with paler ventral side. Legs covered by brown and black setae. Abdomen dark brown with black sclerotized parts. Ostioles of dorsal abdominal glands dark brown. Tip of abdomen black. Setae on head, thorax, and abdomen black. Legs with brown and black setae.

Structure: Body dull with shiny parts of head and thorax, covered by short setae. Head and thorax as well as sclerotized parts of the abdomen with large and very small granulations. Ecdysial line in the middle part wshaped and connected with longitudinal ecdysial line placed in over $1 / 2$ of postocular part of the head and on the neck. Postocular part of the head distinctly gibbous in the area of ocellar tubercles. Clypeus, mandibular, and maxillary plates covered by medium-sized setae. Mandibular plates distinctly visible, covering the basal part of clypeus in lateral view. Labrum wide, visible in over $1 / 2$ of basal part of first visible labial segment. Labium covered by dense, medium-sized, regularly arranged setae. Scapus short, wide, and slightly curved, covered by short, suberected, and robust setae. Pedicellus covered by suberected, medium-sized, short setae. Basiflagellomere the longest, covered by short, thin, adherent, and regularly placed setae. Distiflegallomere covered by regularly arranged and long setae (brown and pale) and by short, suberected, pale setae. Collar of pronotum with large lateral calli and small, regularly arranged granulations. On anterior margin of collar, two lines of medium-sized setae placed parallel and subparallel to the neck. Each calli with one conical granule. Tergite of prothorax with diagonal sulci placed between lines of large granulations and with two distinct concaves in anterior part. Pterothorax covered by short setae and granulations (distinctly visible areas without granulations). Lateral margins of tergites of thorax covered by medium-sized and very dense setae and with visible pale spots in apical part of each margin. Pterothorax with distinctly visible wing pads, covered by small various-sized granulations and medium-sized setae placed on lateral margin. Pro-, meso-, and metaepleura with numerous, small, regularly arranged granulations. Conical spines on the sides of stridulitrum with one long setae placed apically. Pro- and mesocoxal cavities almost completely sclerotized. Unsclerotized parts of metathorax as well as posterior part of mesothorax with slightly visible, very scarce punctuation. Legs covered by various-sized setae, visibly much denser on ventral side. Abdomen dorsally covered by short setae. Evaporatory area of first abdominal gland distinctly visible. On each abdominal segment, visible medium-sized setae placed on 
distinct sclerotized plates and arranged in transversal rows. Muscle attachments very distinctly visible in lateral parts of III to VIII abdominal segment in dorsal and ventral view. Dorsolateral sclerotizations covered by medium-sized setae visible on abdominal segments III to IX. Ostioles of dorsal abdominal glands visible on segments IV to VI (ostiole on segment VI smaller). Segments IX and $\mathrm{X}$ with visible sclerotized plates of tergites. Ventral side of abdomen flattened, covered by transversal rows of long and thin setae and with distinctly visible dark spiracles and two rows of muscle attachments. A sclerotization of sternites in middle part visible on abdominal segments VIII and IX (both connected); sclerotizations covered by long and very short setae.

Measurements (in $\mathrm{mm}$ ): Body length: 26.5 to 28.2; head length: 4.1 to 4.2 ; head width: 3.9 to 3.95 ; length of anteocular part: 2.1 to 2.15 ; length of postocular part: 1.25 to 1.3 ; length of synthlipsis: 1.8 to 1.83 ; lengths of antennal segments I:II:III:IV: 2.28 to 2.31 : 6.68 to 6.72 : 5.1 to 5.22 : 4.31 to 4.34 ; lengths of rostral segments I:II: III: 2.1 to $2.2: 2.25$ to 2.31 : 1.05 to 1.1 ; maximum length of thorax: 6.96 to 7.05 ; maximum width of thorax: 5.8 to 5.9; maximum width of abdomen: 10.1 to 10.5 ; maximum length of abdomen: 10.22 to 10.35 .

For detailed photo of nymphs stages, see Additional file 3.

\section{Evaluation of model and the importance of environmental predictors}

The mean AUC was 0.834, indicating a good discriminatory capacity of the model. The jackknife test (see Additional file 2) showed that the environmental variable with highest gain when used in isolation was temperature seasonality (Bio04) followed by tree cover (Tree_cover), and the variable that decreased the gain the most when it was omitted was also tree cover and Bio04. Thus, these variables appear to have the most useful information by themselves. They also contain a significant portion of information that is not contained in the other variables.

Other variables used in the model were mean diurnal range (Bio02), minimal temperature of coldest month (Bio06), precipitation of driest month (Bio14), and precipitation seasonality (Bio15). Temperature variables (Bio02 and Bio06) were of greater importance as variables that carried the most useful information by themselves, while the precipitation variables (Bio14 and Bio15) decreased the gain when they were omitted.

For Maxent model outputs, see Additional file 2.

\section{The potential species distribution}

The resulting map shows the median of the 50 model replicates output grid. The median was used because it is much more resistant to outliers as an average than the arithmetic mean. As the logistic output was used and the result in values ranging from 0 to 1 was given, an output map with four ranges of presence probability of suitable habitat was created: $0 \%$ to $25 \%$ as unsuitable habitat, $25 \%$ to $50 \%$ as acceptable habitat, $50 \%$ to $75 \%$ as quite suitable and over $75 \%$ as suitable habitat (Figure 3) (Additional file 3).

See Additional file 2 for plots that show how the distribution of occurrence records of P. biguttatus refers to the used predictors.

$P$. biguttatus can be quite widespread in Africa. According to the model, the most suitable areas for this species were mainly restricted to the western part of Senegal, Gambia and Guinea Bissau, the south-western part of Guinea, Sierra Leone and Liberia, the southern part of Ivory Coast, Ghana, Togo, Benin and Nigeria, the south-western part of Cameroon, and the north-western part of Equatorial Guinea, as well as the western part of Angola and the north-western part of Namibia. There were also potentially suitable areas nearby Lake Mai-Ndombe and Lake Tumba in the Democratic Republic of Congo, and at the north of these lakes in the basin of the river Congo. In the eastern part of the African continent, suitable areas were found in the central part of Somalia, the eastern part of Kenya, the south-eastern part of Tanzania and the north-eastern part of Mozambique, as well as in the vicinity of the African Great Lakes, in Zanzibar, Comoros, Mayotte, and the northern and eastern parts of Madagascar.

\section{The niche overlap between $P$. biguttatus and $P$. rhadamanthus}

By comparing the results for overlap between the potential niches of $P$. biguttatus and $P$. rhadamanthus, it was found that at a threshold of 0.25 (which means that the area of more than $25 \%$ was considered to be potentially useful for the species and any data values below the threshold was classified as unsuitable habitat), $14 \%$ of the area considered to be potentially suitable for both species may be a common niche (on a continental scale). However, with a threshold of 0.5 (50\%), this value decreases to $4 \%$. At the 0.25 threshold, common areas are mainly located in the south of Ivory Coast, Ghana, Togo and Benin, Central African Republic, in the center of Ethiopia, in the south of Congo, and in the Democratic Republic of the Congo outside the territory of Congo Basin, as well as in the area of Angola, Uganda, Rwanda, Burundi, Kenya, Tanzania, Zambia, Malawi, Mozambique, South Africa, and Madagascar. At the 0.5 threshold, common areas are restricted to the areas in Central African Republic, Congo, Democratic Republic of the Congo, Uganda, Kenya, Tanzania, and Mozambique (for the results see the Additional file 3 ).

\section{The climatic preferences}

The most important factors affecting species distributions, because of the continental range used in the 


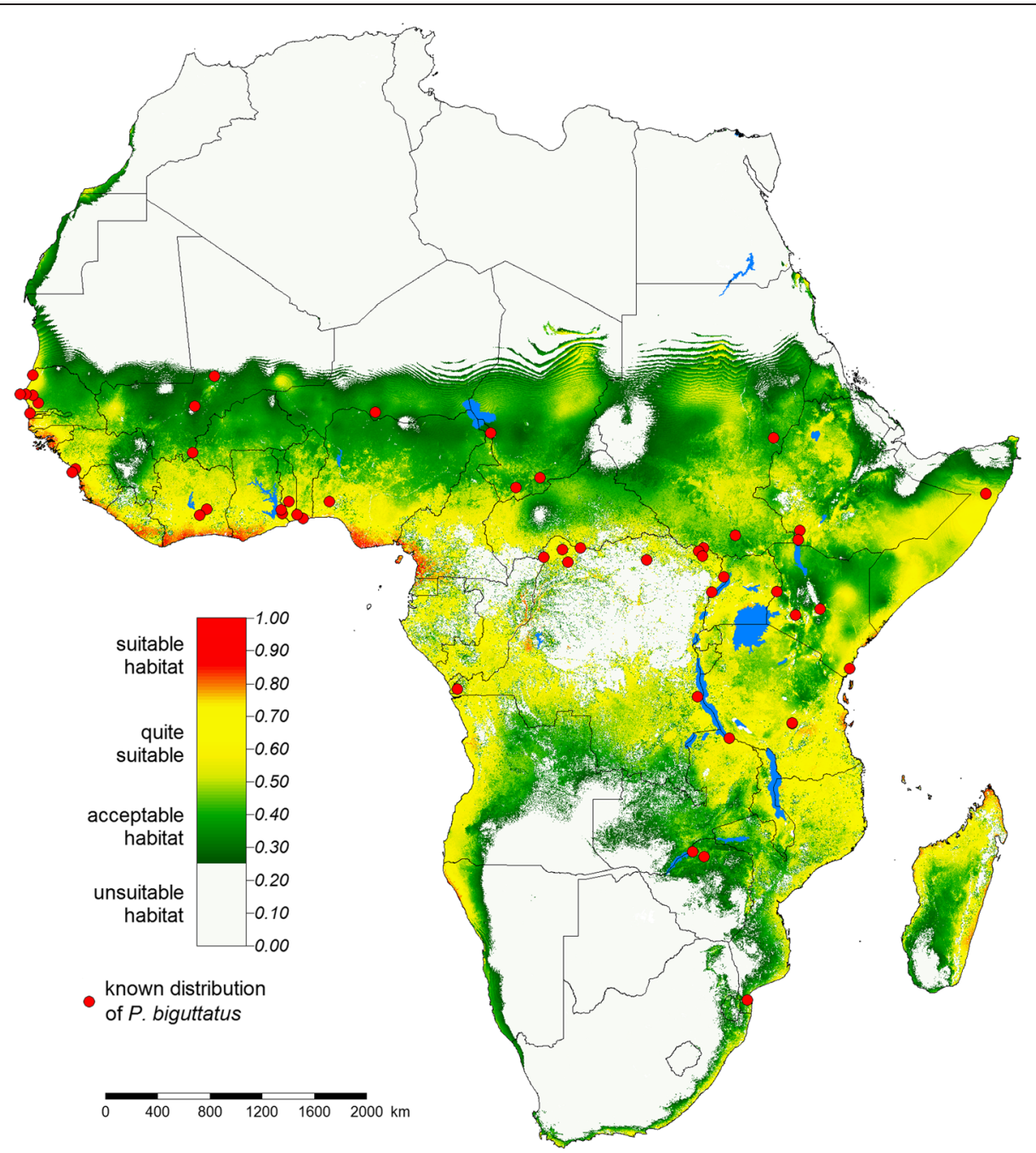

Figure 3 Map of potentially suitable niches for $\boldsymbol{P}$. biguttatus. Predicted probability of presence of a suitable niche in Africa according to selected variables; the legend indicates the presence probability in percentage. Inland continuous lines represent country boundaries.

model, were climate variables. Possible climatic preferences of this species were inferred by comparing potential ecological niches to the Köppen-Geiger climate classification.

The analysis of climate data from known localities of $P$. biguttatus shows that it prefers places with an average annual temperature of about $24.8^{\circ} \mathrm{C}\left(76.6^{\circ} \mathrm{F}\right)$ and a maximum up to $28.6^{\circ} \mathrm{C}\left(82.5^{\circ} \mathrm{F}\right)$. The precipitation in the driest month (Bio14) oscillates about $11 \mathrm{~mm} / \mathrm{m}^{2}$, while an average of annual precipitation is equal to $1,164 \mathrm{~mm} / \mathrm{m}^{2}$, and values above $2,000 \mathrm{~mm} / \mathrm{m}^{2}$ in individual cases.

By assigning to the locations of the occurrence of $P$. biguttatus the mean temperature and mean total precipitation for each month, a climatic diagram was created (Figure 4). The diagram shows a clear correlation between the increase of precipitation and the decrease of temperature. Tropical savanna climate is a grassland biome, located in regions of subtropical and tropical latitudes. It is characterized by periods of low precipitation and higher thermal amplitudes in the annual and diurnal cycle than in typical tropical climates.

\section{Discussion}

To provide some new information about niche preferences as well as potential distributions of P. biguttatus, the ecological niche modeling method was used. Because many specimens obtained from museums were collected from the same location, in order to avoid model disturbances by strong intercorrelations, duplicate records were removed to prevent unnecessary strengthening of points (Veloz 2009). A bias grid was also used to upweight records with few neighbors in geographic space (Elith et al. 2010).

Because the presented model was built with climatic, tree cover, and elevation data layers, and it employed the continental range, it mainly allowed for drawing conclusions about the possible climatic preferences of the 


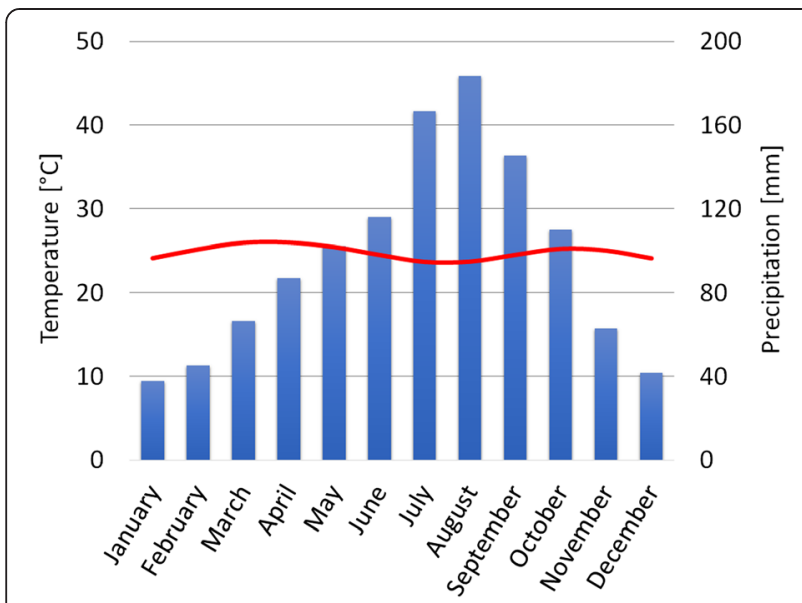

Figure $\mathbf{4}$ Climate diagram of the distribution of air temperature and precipitation. Line shows the temperature distribution during the year and bars represent the distribution of precipitation throughout the year. For each month, the average value from all known locations of this species is given.

species (see Dungan et al. 2002). Elevation data proved unimportant to the model, but the climate variables showed the possible tolerance ranges for temperatures and precipitations.

The analysis of climate classification shows that most of the potentially suitable niches suggested by the model for P. biguttatus were in the area of tropical savanna climate - with a pronounced dry season and monthly mean temperature above $18^{\circ} \mathrm{C}\left(64^{\circ} \mathrm{F}\right)$ in every month of the year. Some of potentially suitable niche areas were also present in the area of hot semi-arid climate, mainly in Ethiopia, Somalia, Kenya, and Tanzania. This kind of climate is characterized by hot summers and mild to warm winters. Areas with this type of climate are usually dominated by grasses and/or shrubs, because of the low precipitation during the year (but the short wet season is well-defined).

As well as other representatives of Reduviidae, $P$. biguttatus is predatory, preying on several different species of prey. For this reason, it is difficult to use biotic interactions in the model, but the analysis of the results from tree cover layer gives a picture of the habitat preferences of the species - open areas with small participation of tree vegetation but also away from the typical desert areas. We believe that this is a characteristic of the food preferences of its prey (grassy vegetation), so the tolerance to climatic factors of this species may be much wider.

Some of the data from unidentified materials (marked with * in the Additional file 1) supports the results of modeling by confirmation of presence of the suitable niche for example in Sierra Leone, Cameroun, or Ghana. Those materials have not been used in the modeling process because of the fact that the description of these specimens contained only the country in which they were collected, without the exact location.

It is worth noting that the model suggests suitable conditions for P. biguttatus in the area of Madagascar. There is a geographical barrier which does not allow it to penetrate to the island; however, its introduction could threaten the local fauna.

It should be remembered that even if the model suggests some locations as potentially suitable, the species could be absent there (Anderson 2003; Martínez-Meyer 2005). It is not possible to take into account all the potential environmental factors, like the presence of another predator or lack of prey resources. Therefore, it would be very worthwhile to carry out some field studies to test the hypothesis of a potential distribution and also to obtain data on the ecology of this species and to improve knowledge about its prey in a natural environment.

\section{Conclusions}

A description of each nymphal instars of $P$. biguttatus (L.) has been carried out. So far it was only known that this species occurs in widely understood tropical part of continental Africa. The ecological niche modeling methods could be performed thanks to the museum data on the occurrence of the species. It resulted in new information about potentially suitable ecological niches and the possible range of distribution. Moreover, it provides valuable information about climatic preferences of the species and allows for comparison of niche overlap.

\section{Additional files}

Additional file 1: Detailed list of examined materials. Detailed list of examined materials, which provided the information about occurrence localities; map of the actual distribution of $P$. biguttatus.

Additional file 2: Occurrence localities, Maxent model outputs and distribution of the occurrence records in relation to used predictors. Details of all occurrence localities used in the Maxent model, Maxent model outputs and analysis of variable contributions for P. biguttatus.

Additional file 3: Detailed maps. Detailed maps of potentially suitable niches for $P$. biguttatus.

\section{Competing interests}

The authors declare that they have no competing interests.

\section{Authors' contributions}

DC performed taxonomic analysis and collected data on the occurrence of specimens; drafted the manuscript. AB-N performed ecological niche modeling; analyzed the data on the occurrence; analyzed climatic preferences of the species; prepared photos, maps, and diagrams; drafted the manuscript. $Ł J$ prepared drawings. Authors have read and approved the final manuscript.

\section{Acknowledgements}

We are very grateful to E. De Coninck (MRAC), J. Constant (IRSNBG), J. Deckert (ZMB), E. Guilbert (MNHN), G. Lindberg (NHRS), A. Orosz and D. Rédei (HMNH), M. Webb (BMNH), and H. Zettel (NMW) for all their kind help and hospitality during the first author's visit in the collections. 
Received: 12 July 2014 Accepted: 23 December 2014

Published online: 09 January 2015

\section{References}

Aguirre-Gutiérrez J, Carvalheiro LG, Polce C, van Loon EE, Raes N, Reemer M et al (2013) Fit-for-purpose: species distribution model performance depends on evaluation criteria - Dutch hoverflies as a case study. PLoS One 8(5):406, e63708 Anderson RP (2003) Real vs. artefactual absences in species distributions: tests for Oryzomys albigularis (Rodentia: Muridae) in Venezuela. J Biogeogr 30:591-605

Beck J (2012) Predicting climate change effects on agriculture from ecological niche modeling: who profits, who loses? Clim Chang 116:177-189

Berzitis EA, Minigan JN, Hallett RH, Newman JA (2014) Climate and host plant availability impact the future distribution of the bean leaf beetle (Cerotoma trifurcata). Glob Chang Biol. doi:10.1111/gcb.12557

Chłond D, Bugaj-Nawrocka A (2014) Model of potential distribution of Platymeris rhadamanthus Gerstaecker, 1873 with redescription of species. Zool Stud 53:8

DeFries R, Hansen M, Townshend JRG, Janetos AC, Loveland TR (2000) A new global $1 \mathrm{~km}$ data set of percent tree cover derived from remote sensing. Glob Chang Biol 6:247-254

Dungan $J$, Perry JN, Dale MRT, Legendre P, Citron-Pousty S, Fortin M-J et al (2002) A balanced view of scale in spatial statistical analysis. Ecography 25:626-640

Elith J, Graham CH, Anderson RP, Dudik M, Ferrier S, Guisan A et al (2006) Novel methods improve prediction of species' distributions from occurrence data. Ecography 29:129-151

Elith J, Kearney M, Phillips S (2010) The art of modelling range-shifting species. Methods Ecol Evol 1:330-342

Elmore AJ, Julian JP, Guinn SM, Fitzpatrick MC (2013) Potential stream density in Mid-Atlantic U.S. watersheds. PLoS One 8(8):e74819

Fielding AH, Bell JF (1997) A review of methods for the assessment of prediction errors in conservation presence/absence models. Environ Conserv 24:38-49

GLOBE Task Team and others (1999) In: Hastings DA, Dunbar PK, Elphingstone GM, Bootz, M, Murakami H, Maruyama H, Masaharu H, Holland P, Payne J, Bryant NA, Logan TL, Muller J-P, Schreier G, MacDonald JS (eds) The Global Land Onekilometer Base Elevation (GLOBE) Digital Elevation Model, Version 1.0. National Oceanic and Atmospheric Administration, National Geophysical Data Center, 325 Broadway, Boulder, Colorado 80305-3328, USA. Digital Database on http://www.ngdc.noaa.gov/mgg/topo/globe.html and CD-ROMs (accessed 16 November 2014)

Google Inc (2013) Google Earth, version 7.2.1.2041 [Software]. Available from https://www.google.com/earth/

Hernandez PA, Graham CH, Master LL, Albert DL (2006) The effect of sample size and species characteristics on performance of different species distribution modeling methods. Ecography 29:773-785

Hijmans RJ, Cameron SE, Parra JL, Jones PG, Jarvis A (2005) Very high resolution interpolated climate surfaces for global land areas. Int J Climatol 25:1965-1978

Laporte FL (1833) Essai d'une classification systematique de l'ordre des Hémiptères (Hémiptéres Hétéroptères, Latr.). Mag Zool (ser 2) 1:1-88, plus supplement

Li H, Zhao G, Cao L, Xu K, Cai W (2010) Taxonomic and bionomic notes on the white spot assassin bug Platymeris biguttatus (Linnaeus) (Hemiptera: Reduviidae: Reduviinae). Zootaxa 2644:47-56

Linnaeus C (1767) Systema Naturæ per regna tria naturæ, secundum classes, ordines, genera, species, cum characteribus, differentiis, synonymis, locis. Editio duodecima, reformata. Tomus II. Laurentius Salvius, Holmiae

Maldonado Capriles J (1990) Systematic catalogue of the Reduviidae of the world (Insecta: Heteroptera). (Special edition of the Caribbean Journal of Science). University of Puerto Rico, Mayagüez, Puerto Rico

Martínez-Meyer E (2005) Climate change and biodiversity: some considerations in forecasting shifts on species' potential distributions. Biodivers Inform 2:42-55

Ochoa-Ochoa L, Urbina-Cardona JN, Vázquez L-B, Flores-Villela O, Bezaury-Creel J (2009) The effects of governmental protected areas and social initiatives for land protection on the conservation of Mexican amphibians. PLoS One 4(9):e6878

Papeş M, Gaubert P (2007) Modelling ecological niches from low numbers of occurrences: assessment of the conservation status of poorly known viverrids (Mammalia, Carnivora) across two continents. Divers Distrib 13:890-902

Pearce J, Ferrier S (2000) Evaluating the predictive performance of habitat models developed using logistic regression. Ecol Model 133(3):225-245

Peel MC, Finlayson BL, McMahon TA (2007) Updated world map of the Köppen-Geiger climate classification. Hydrol Earth Syst Sci 11:1633-1644

Phillips SJ, Dudík M (2008) Modelling of species distributions with Maxent: new extensions and a comprehensive evaluation. Ecography 31:161-175
Phillips SJ, Anderson RP, Schapire RE (2006) Maximum entropy modeling of species geographic distributions. Ecol Model 190:231-259

Raes N, ter Steege H (2007) A null-model for significance testing of presence-only species distribution models. Ecography 30:727-736

R Development Core Team (2011) R: a language and environment for statistical computing (version 3.0.2). R Foundation for Statistical Computing, Vienna, Austria

SAGA Development Team (2013) System for Automated Geoscientific Analyses (SAGA) (version 2.1.0). Institute of Geography at the University of Hamburg, Germany

Solhjouy-Fard S, Sarafrazi A (2013) Potential impacts of climate change on distribution range of Nabis pseudoferus and N. palifer (Hemiptera: Nabidae) in Iran. Ent Sci 17(3):283-292

Stohlgren TJ, Jarnevich CS, Esaias WE, Morisette JT (2011) Bounding species distribution models. Curr Zool 57(5):642-647

Veloz SD (2009) Spatially autocorrelated sampling falsely inflates measures of accuracy for presence-only niche models. J Biogeogr 36:2290-2299

Wieczorek K, Bugaj-Nawrocka A (2014) Invasive Aphids of the Tribe Siphini: Mode of Potentially Suitable Ecological Niche. Agric For Entomol 16:434-443

Williams GJ (2011) Data mining with Rattle and R: the art of excavating data for knowledge discovery. Use R! series. Springer-Verlag, Heidelberg

Wisz MS, Hijmans RJ, Li J, Peterson AT, Graham CH, Guisan A et al (2008) Effects of sample size on the performance of species distribution models. Divers Distrib 14:763-773

\section{Submit your manuscript to a SpringerOpen ${ }^{\odot}$ journal and benefit from:}

- Convenient online submission

- Rigorous peer review

- Immediate publication on acceptance

- Open access: articles freely available online

- High visibility within the field

- Retaining the copyright to your article

Submit your next manuscript at springeropen.com 